\title{
PENGARUH PENAMBAHAN KEONG MAS (Pomacea canaliculata) TERHADAP PERUBAHAN SIFAT KIMIA ULTISOL
}

\author{
Oktanis Emalinda, Adnawita, Eti Farda Husin \\ J urusan Tanah Faperta Unand
}

\begin{abstract}
To look for the effect of gold snail (Pomacea canaliculata) addition on soil nutrition level, a series of pot experiment was conducted in Faculty of Agriculture and P3IN laboratories from March to June 2008. This study used completely randomized design with 2 kinds of treatments. First iwas gold snail composition $(\mathrm{A1}=$ snail shell, $\mathrm{A2}=$ snail body, and $\mathrm{A3}=$ whole snail $)$ and incubation period $(B 1=2$ weeks, $B 2=3$ weeks, and $B 3=4$ weeks). The results showed that these treatments affect some of soil chemical properties. Soil $\mathrm{pH}$ changed from acid to slightly acid, total nitrogen rose from low to medium, exchangeable base cations also increased. On the other hand, exchangeable aluminum (Al) decreased. Interaction between the treatments successfully increased organic carbon, available phosphorous, and cation exchange capacity. The best treatment combination was between body composition of gold snail and a four-week incubation period.
\end{abstract}

Key Words: gold snail, U Itisols, soil chemical characteristics

\section{PENDAHULUAN}

Tanah mempunyai peranan penting dalam produksi hasil pertanian. Pertambahan jumlah penduduk di Indonesia menyebabkan kebutuhan akan hasil pertanian juga meningkat. Terjadinya alih fungsi lahan secara besar-besaran,. Mengakibat kan lahan-lahan yang tersedia untuk pertanian adalah lahan marginal yang memiliki tingkat kesuburan rendah, namun tetap diusahakan sebagai lahan pertanian dengan mengikuti kaidah konservasi. Terkait dengan permasalahan yang ada pada Ultisol, maka perlu dilakukan usaha perbaikan antara lain penambahan bahan organik sehingga dapat dimanfaatkan secara optimal sebagai lahan pertanian. Salah satu yang dapat dijadikan sebagai sumber bahan organik adalah keong mas (Pomacea canaliculata). Hal ini disebabkan karena daging keong mas mengandung beberapa unsur hara yang dibutuhkan tanaman. Sebastian (2000) menginformasikan bahwa dalam $100 \mathrm{~g}$ daging keong mas mengandung beberapa unsur hara antara lain: Fospor sebanyak $60 \mathrm{mg}$, Kalium (K) $17 \mathrm{mg}$ serta berbagai unsur hara lainnya seperti : $\mathrm{C}, \mathrm{Mn}$, Cu dan Zn. Kemudian ditambahkan oleh Pitojo (1996) bahwa cangkang keong mas mengandung unsur Kalsium Karbonat $\left(\mathrm{CaCO}_{3}\right)$. Penambahan keong mas yang dicampurkan ke dalam tanah diharapkan bisa memperbaiki sifat, kimia maupun biologi tanah. Selama ini keberadaan keong 
mas menjadi masalah terutama bagi tanaman padi, sehingga dapat menurunkan produksi padi

Dengan menjadikan keong mas sebagai bahan organik, disamping dapat memperbaiki sifat tanah juga dapat mengurangi kerugian yang ditimbulkan keong mas pada tanaman padi selama ini. Berlatar belakang dari uraian di atas maka penulis telah melakukan penelitian dengan judul "Pengaruh Penambahan Keong Mas (Pomacea canaliculata)" terhadap Penubahan Sifat Kimia Ultisol. Adapun tujuan penelitian ini adalah untuk mendapatkan komposisi dan lama inkubasi terbaik keong mas terhadap perbaikan sifat kimia Ultisol.

\section{BAHAN DAN METODA}

Penelitian di laksanakan dari bulan Maret sampai Juni 2008 di Laboratorium Tanah Fakultas Pertanian dan Laboratorium Pusat Penelitian Pemanfaatan Iptek Nuklir (P3IN) Universitas Andalas Padang. Penelitian ini menggunakan Rancangan Faktorial dalam RAL, terdiri dari 2 faktor. Faktor A (Komposisi Keong Mas) dan faktor B (Lama Inkubasi Keong Mas) masing-masing 3 ulangan. Faktor A (Komposisi Keong Mas), yang terdiri dari :A1 = Cangkang Keong Mas,A2 = Daging Keong Mas,A3 = Cangkang + daging Keong Mas.Faktor B (Lama Inkubasi) terdiri dariB1 $=2$ minggu,B2 $=3$ minggu, dan $B 3=4$ minggu. Untuk mengetahui perubahan sifat kimia tanah hasil analisis setelah perlakuan dibandingkan dengan hasil analisis sebelum perlakuan

Pengambilan tanah dilakukan secara komposit pada kedalaman 0-20 cm. Tanah dikering anginkan, dibersihkan kemudian diayak dengan ayakan 2 mm, dan diambil sampel tanah sebanyak $200 \mathrm{~g}$ untuk analisis tanah awal. Untuk perlakuan tanah dimasukkan ke dalam baki yang masingmasingnya 8 kg/baki setara kering mutlak Antara daging dan cangkang keong mas dipisahkan. Kemudian dihancurkan sampai ukuran $\pm 2 \mathrm{~mm}$, masing-masingnya ditimbang 80 g/baki (setara kering mutlak), bagian cangkang taraf $A_{1}$, daging taraf $A_{2}$ dan untuk taraf $\mathrm{A}_{3}$ Cangkang + daging keong mas, jumlah cangkang adalah $40 \mathrm{~g}$ setara kering mutlak dan daging $40 \mathrm{~g}$ setara kering mutlak.Tanah yang telah dimasukkan ke dalam baki ditambahkan keong mas dengan takaran 20 ton/ha yang setara dengan 80 g/baki. Setelah itu tanah diaduk secara merata, kemudian ditambahkan air sampai kapasitas lapang. Kemudian ditutup dengan plastik hitam dan diinkubasi sesuai waktu perlakuan. Analisis tanah awal dan analisis tanah setelah inkubasi dilakukan terhadap: pH tanah, Al-dd, C-organik, N total, P tersedia, KTK, serta Ca, Mg, K, Nadd tanah.

\section{HASIL DAN PEMBAHASAN}

Analisis beberapa kandungan unsur hara yang terdapat pada keong mas yang digunakan dalam penelitian ditampilkan 
dalam tabel 1. berikut ini

Tabel 1. Hasil Analisis Kandungan Unsur Hara pada Keong Mas

\begin{tabular}{|c|c|c|c|}
\hline \multirow{2}{*}{ No } & \multirow{2}{*}{ Jenis Analisis } & \multicolumn{2}{|c|}{ Jumlah Unsur } \\
\hline & & Cangkang & Daging \\
\hline 1. & C-Organik (\%) & 3,44 & 13,53 \\
\hline 2. & Fospor $(\mathbf{P})(\mathbf{p p m})$ & $\mathbf{0 , 5 7}$ & 2,56 \\
\hline 3. & Nitrogen $(\mathrm{N})(\%)$ & 0,49 & 13,72 \\
\hline 4. & Kalium (K) (ppm) & 1,99 & 5,36 \\
\hline 5. & Natrium (Na) (ppm) & 2,75 & 5,92 \\
\hline 6. & Kalsium (Ca) (ppm) & 28,33 & 6,61 \\
\hline 7. & Seng $(Z n)(p p m)$ & 1,27 & 1,24 \\
\hline 8. & Tembaga (Cu) (ppm) & 0,18 & 0,51 \\
\hline
\end{tabular}

Dari Tabel terlihat adanya potensi keong mas sebagai sumber bahan organik dan hara yang bisa memperbaiki kesuburan tanah.

Tabel 2. Hasil Analisis awal beberapa Sifat Kimia Ultisols

\begin{tabular}{|c|c|c|c|}
\hline No & Sifat Kimia Tanah & Nilai & Kriteria \\
\hline \multirow[t]{2}{*}{1.} & pH H $\mathrm{H}_{2} \mathrm{O}(1: 1)$ & 5,01 & Masam \\
\hline & pH KCl (1:1) & 4,18 & Masam \\
\hline 2. & C-Organik (\%) & 0,28 & Sangat rendah \\
\hline 3. & N-Total (\%) & 0,13 & Rendah \\
\hline 4. & P-Tersedia (ppm) & 7,68 & Sangat rendah \\
\hline 5. & KTK (me/100g) & 11,37 & Rendah \\
\hline 6. & K-dd (me/100 g) & 0,05 & Sangat rendah \\
\hline 7. & Ca-dd (me/100g) & $\mathbf{0 , 7 0}$ & Sangat rendah \\
\hline 8. & Mg-dd (me/100g) & 0,24 & Rendah \\
\hline 9. & Na-dd (me/100 g) & 0,36 & Sangat rendah \\
\hline 10. & $\mathrm{Cu}(\mathrm{ppm})$ & 4,85 & Sangat Rendah \\
\hline 11. & Zn (ppm) & 45,12 & Rendah \\
\hline 12. & Al-dd (me/100 gr) & 3,12 & - \\
\hline
\end{tabular}

Berdasarkan Tabel 2 di atas secara umum menggambarkan bahwa Ultisol yang digunakan dalam penelitian ini memiliki tingkat kesuburan yang sangat rendah..
Rendahnya tingkat kesuburan Ultisol perlu diperbaiki agar bisa dioptimalkan sebagai lahan pertanian. Salah satu usaha yang dapat dilakukan untuk memperbaiki kesuburan 
tanah ini adalah dengan penambahan bahan organik. Sumber bahan organik yang Analisis Tanah Setelah Perlakuan

Tabel 3. Hasil Analisis pH tanah setelah perlakuan.

\begin{tabular}{|c|c|c|c|}
\hline \multirow{2}{*}{ Komposisi keong mas (A) } & \multicolumn{3}{|c|}{ Lama Inkubasi (B) } \\
\hline & 2 minggu & 3 minggu & 4 minggu \\
\hline Cangkang & $5,91(\mathrm{am}) * \mathrm{~A} \mathbf{c}$ & $5,78(\mathbf{a m}) *$ B b & $5,5(\mathrm{~m}) * \mathrm{C} \mathrm{b}$ \\
\hline Daging & $5,98(\mathrm{am}) * \mathrm{~B}$ b & $\mathbf{6 , 0 9}(\mathbf{a m}) * \mathbf{A} \mathbf{a}$ & $5,94(\mathrm{am}) * \mathrm{C} \mathrm{a}$ \\
\hline Cangkang + Daging & $5,53(\mathrm{~m}) * \mathrm{~A} \mathrm{a}$ & $5,75(\mathbf{a m}) * \mathrm{~B}$ b & $6,20(\mathrm{am}) * \mathrm{C} b$ \\
\hline KK & $0,57 \%$ & & \\
\hline
\end{tabular}

digunakan dalam penelitian ini adalah keong mas, yang diharapkan bisa memperbaiki sifat kimia tanah.

Reaksi tanah (pH) setelah ditambahkan keong mas dengan komposisi dan lama inkubasi yang berbeda dapat meningkat dari masam menjadi agak masam, kecuali pada perlakuan $A_{1} B_{3}$ dan $A_{3} B_{3}$ tidak terjadi perubahan kriteria $\mathrm{pH}$ tanah,

Terjadinya peningkatan $\mathrm{pH}$ masingmasing perlakuan diduga adanya sumbangan unsur Na (Natrium) dari keong mas yang ditambahkan, dimana pada analisis keong mas yang digunakan dalam penelitian ini mengandung $\mathrm{Na}$ 2,75 ppm pada cangkang dan $\mathbf{5 , 9 2}$ ppm pada dagingnya. Disamping itu dari analisis Nadd yang dilakukan juga terjadi peningkatan Na-dd dari tanah awal. Pada tabel 3 dapat dilihat bahwa penambahan Cangkang + daging keong mas $\left(\mathrm{A}_{1}\right)$ mengalami kenaikan pH yang lebih tinggi dibandingkan perlakuan A $A_{1}$ dan $A_{2}$ pada lama inkubasi 2 minggu.
Adanya interaksi yang nyata berupa peningkatan dan penurunan $\mathrm{pH}$ tanah menunjukkan bahwa terjadinya perubahan yang tidak sama setelah ditambahkan keong mas dengan komposisi dan lama inkubasi yang berbeda. Hal ini disebabkan kebutuhan lama dekomposisi yang berbeda - beda masing - masing bahan keong mas yang ditambahkan. Ada bahan yang cepat terdekomposisi dan ada yang embutuhkan waktu yang lama untuk terdekomposisi. Nilai pH tertinggi ditemukan pada perlakuan $A_{3} B_{1}$ (Cangkang + daging keong mas dan lama inkubasi 2 minggu). Sedangkan Pada perlakuan $\mathbf{A}_{3} \mathbf{B}_{2}$ (cangkang keong mas dan lama inkubasi 3 minggu) dan perlakuan $\mathrm{A}_{3} \mathrm{~B}_{3}$ ( cangkang + daging keong mas dan lama inkubasi 4 minggu) $\mathrm{pH}$ tanah mengalami penurunan. Turunnya pH tanah diduga akibat adanya aktivitas mikroorganisme dalam merombak keong mas yang ditambahkan ke dalam tanah. Pada saat terjadinya perombakan tersebut dihasilkan asam-asam organik, asam-asam 
organik ini mempunyai gugus fungsional

Tabel 4. Hasil Analisis Al-dd tanah setelah perdakuan.

\begin{tabular}{llll}
\hline \multirow{2}{*}{ Komposisi Keong Mas (A) } & \multicolumn{3}{c}{ Lama Inkubasi (B) } \\
\cline { 2 - 4 } & 2 minggu & 3 minggu & 4 minggu \\
\hline Cangkang & 1,59 & 1,14 & 0,68 \\
Daging & tu & tu & tu \\
Cangkang + Daging & 0,91 & tu & tu \\
\hline
\end{tabular}

tu $=$ tidak terukur

yang mendisosiasikan ion $\mathrm{H}^{+}$sehingga konsentrasi ion $\mathrm{H}^{+}$menjadi lebih banyak dan menyebabkan pH tanah turun.

Untuk Al-dd tanah, terjadi penurunan setelah perlakuan. Nilai rata-rata Al-dd setelah perlakuan dapat dilihat pada Tabel 4.Pada tabel 4 dapat lihat bahwa penambahan keong mas dengan komposisi dan lama inkubasi yang berbeda mampu menurunkan Al-dd tanah. Penambahan keong mas dengan komposisi yang berbeda dapat menurunkan Al-dd tanah seiring dengan lama inkubasi yang berbeda. Semakin lama inkubasi maka semakin besar penurunan Al-dd.Terjadinya penurunan Aldd diduga karena terbentuknya senyawasenyawa komplek antara Al dengan asamasam organik yang dihasilkan selama proses dekomposisi keong mas yang ditambahkan. Meskipun tidak terlihat pengaruh yang signifikan, tetapi tetap terjadinya peningkatan nilai C-Organik tanah dari tanah awal. Masing-masing perlakuan $A_{1} B_{1}$; $\mathbf{A}_{2} \mathbf{B}_{1} ; \mathbf{A}_{3} \mathbf{B}_{1} ; \mathbf{A}_{1} \mathbf{B}_{2} ; \mathbf{A}_{2} \mathbf{B}_{2} ; \mathbf{A}_{3} \mathbf{B}_{2} ; \mathbf{A}_{1} \mathbf{B}_{3} ; \mathbf{A}_{2} \mathbf{B}_{3}$ dan $A_{3} B_{3}$ sebesar : 0.39; 0,45; 0,27; 0,59; 0,$66 ; 0,67 ; 0,71 ; 0,60$ dan $0,54 \% . A p a b i l a$ dibandingkan dengan kriteria $\mathrm{N}$-total tanah maka terlihat terjadinya pengaruh penambahan keong mas dengan komposisi dan lama inkubasi yang berbeda terhadap $\mathrm{N}$ total tanah. Hal ini ditandai dengan terjadinya peningkatan kriteria $\mathrm{N}$-total tanah dari rendah menjadi sedang, nilai $\mathrm{N}$-total tanah sebelum perlakuan adalah $0,125 \%$, namun pada perlakuan $A_{1} B_{2}$ dan $A_{1} B_{3}$ tidak terjadi peningkatan kriteria $\mathrm{N}$-total tanah.

Tabel 5. Hasil Analisis C-organik tanah setelah perlakuan.

\begin{tabular}{|c|c|c|c|}
\hline \multirow{2}{*}{ Komposisi Keong Mas (A) } & \multicolumn{3}{|c|}{ Lama Inkubasi (B) } \\
\hline & 2 minggu & 3 minggu & 4 minggu \\
\hline Cangkang & 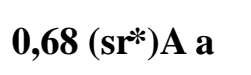 & $0,88\left(\mathbf{s r}^{*}\right) \mathrm{A}$ a & $1,00\left(r^{*}\right) \mathrm{A} a$ \\
\hline Daging & $0,74\left(\mathrm{sr}^{*}\right) \mathrm{A}$ a & $0,95\left(s r^{*}\right) \mathbf{A}$ a & $0,89\left(\mathrm{sr}^{*}\right) \mathrm{A}$ a \\
\hline Cangkang + Daging & $0,56\left(s r^{*}\right) A B$ a & $0,96\left(\mathrm{sr}^{*}\right) \mathrm{A} \mathbf{a}$ & $\mathbf{0 , 8 3}\left(\mathrm{sr}^{*}\right) \mathrm{A}$ a \\
\hline KK & $24,54 \%$ & & \\
\hline
\end{tabular}

* = kriteria C-organik tanah menurut Staf pusat penelitian tanah (1983 cit Hardjowigeno, 2003), $s r=$ sangat rendah $r=$ rendah 
Tabel 6. Hasil Analisis N-Total tanah setelah perlakuan.

\begin{tabular}{|c|c|c|c|}
\hline \multirow{2}{*}{ Komposisi Keong Mas (A) } & \multicolumn{3}{|c|}{ Lama Inkubasi (B) } \\
\hline & 2 minggu & 3 minggu & 4 minggu \\
\hline Cangkang & $0,28\left(\mathrm{sd}^{*}\right) \mathrm{A}$ a & $0,19\left(r^{*}\right)$ B b & $0,18\left(r^{*}\right)$ B b \\
\hline Daging & $0,28\left(\mathrm{sd}^{*}\right) \mathrm{B}$ a & $\mathbf{0 , 3 3}\left(\mathrm{sd}^{*}\right) \mathrm{A} \mathbf{a}$ & $0,21\left(\mathrm{sd}^{*}\right) \mathbf{C} b$ \\
\hline Cangkang + Daging & $0,26\left(\mathrm{sd}^{*}\right) \mathrm{A} \mathbf{a}$ & $0,21\left(\mathrm{sd}^{*}\right) \mathrm{B}$ b & $0,28\left(\mathrm{sd}^{*}\right) \mathrm{A} \mathbf{a}$ \\
\hline KK & $8,39 \%$ & & \\
\hline
\end{tabular}

Nilai $\mathbf{N}$-Total tertinggi ditemukan pada perdakuan $\mathbf{A}_{2} \mathbf{B}_{2}$ (daging keong mas dan lama inkubasi 3 minggu) yaitu $0,33 \%$, tingginya $\mathrm{N}$-total pada perlakuan ini diduga karena adanya sumbangan $\mathrm{N}$ yang besar dari daging keong mas, kemudian terjadinya penurunan N-total pada perlakuan $\mathbf{A}_{2} \mathbf{B}_{3}$ (daging keong mas dan lama inkubasi 4 minggu) menjadi $0,21 \%$. Terjadinya penurunan ini diduga karena $\mathbf{N}$ yang berasal dari proses dekomposisi sebagian digunakan oleh mikroorganisme tanah sebagai nutrisi untuk menjaga kelangsungan hidupnya, diduga dengan inkubasi 4 minggu bahan organik yang berasal dari keong mas telah terurai secara sempurna, sehingga mikroorganisme tidak mendapatkan sumbangan nutrisi lagi selain $N$ yang berasal dari proses dekomposisi. Menurut Hardjowigeno (2003), bahwa salah satu faktor yang menyebabkan kehilangan $\mathbf{N}$ dalam tanah adalah akibat digunakan oleh mikroorganisme.

Pemberian keong mas dengan lama inkubasi yang berbeda tidak berpenganuh terhadap P-tersedia. Yang ditunjukan Tidak adanya perubahan kriteria P-tersedia tanah setelah perlakuan. Meskipun demikian nilai P-tersedia cendrung meningkat dari Ptersedia sebelum perlakuan, masing-masing perlakuan $A_{1} B_{1} ; A_{2} B_{1} ; A_{3} B_{1} ; A_{1} B_{2} ; A_{2} B_{2}$; $A_{3} B_{2} ; A_{1} B_{3} ; A_{2} B_{3}$ mengalami peningkatan yaitu sebesar :2,25; 2,09 ; 0,$68 ; 0,63 ; 1,41$; 1,$19 ; 1,43 ; 0,44$ ppm. Sedangkan perlakuan $\mathrm{A}_{3} B_{3}$ P-tersedia menurun sebesar 0,28 ppm

Tabel 7. Hasil Analisis P-tersedia (ppm) setelah perlakuan.

\begin{tabular}{llllc}
\hline Komposisi Keong & \multicolumn{2}{c}{ Lama Inkubasi $(\mathrm{B})$} & \multicolumn{2}{c}{ Rata-rata } \\
\cline { 2 - 5 } Mas (A) & 2 minggu & 3 minggu & 4 minggu \\
\hline Cangkang & $\mathbf{9 , 9 2}\left(\mathrm{sr}^{*}\right)$ & $\mathbf{7 , 9 4}\left(\mathrm{sr}^{*}\right)$ & $\mathbf{9 , 1 2}\left(\mathrm{sr}^{*}\right)$ & $\mathbf{8 , 9 9}$ \\
Daging & $\mathbf{9 , 7 7}\left(\mathrm{sr}^{*}\right)$ & $\mathbf{9 , 0 8}\left(\mathrm{sr}^{*}\right)$ & $\mathbf{8 , 1 1}\left(\mathrm{sr}^{*}\right)$ & $\mathbf{8 , 9 9}$ \\
Cangkang+ Daging & $\mathbf{8 , 3 5}\left(\mathrm{sr}^{*}\right)$ & $\mathbf{8 , 8 6}\left(\mathrm{sr}^{*}\right)$ & $\mathbf{7 , 3 9}\left(\mathrm{sr}^{*}\right)$ & $\mathbf{8 , 2 0}$ \\
\hline Rata - rata & $\mathbf{9 , 3 5}\left(\mathrm{sr}^{*}\right) \mathrm{A}$ & $\mathbf{8 , 6 3}\left(\mathrm{sr}^{*}\right) \mathrm{A}$ & $\mathbf{8 , 2 0}\left(\mathrm{sr}^{*}\right) \mathrm{A}$ & \\
\hline KK & $\mathbf{9 , 5 7 \%}$ & & & \\
\hline
\end{tabular}


Tabel 8. Hasil Analisis KTK tanah (me/100g) setelah perlakuan.

\begin{tabular}{|c|c|c|c|}
\hline \multirow{2}{*}{ Komposisi Keong Mas (A) } & \multicolumn{3}{|c|}{ Lama Inkubasi (B) } \\
\hline & 2 minggu & 3 minggu & 4 minggu \\
\hline Cangkang & $12,98\left(r^{*}\right) B ~ b$ & $13,10\left(r^{*}\right) B ~ c$ & $15,00\left(r^{*}\right) A ~ a$ \\
\hline Daging & $14,30\left(r^{*}\right)$ B a & $15,38\left(r^{*}\right)$ A a & $15,10\left(r^{*}\right) \mathrm{A}$ a \\
\hline Cangkang + Daging & $13,04\left(r^{*}\right) B$ b & $14,08\left(r^{*}\right) A ~ b$ & $13,20\left(\mathbf{r}^{*}\right) \mathrm{B}$ b \\
\hline KK & $5,28 \%$ & & \\
\hline
\end{tabular}

KTK tanah setelah perdakuan mengalami peningkatan dari tanah sebelum perlakuan. Peningkatan nilai KTK masing masing perlakuan $\mathbf{A}_{1} \mathbf{B}_{1} ; \mathbf{A}_{2} \mathbf{B}_{1} ; \mathbf{A}_{3} \mathbf{B}_{1} ; \mathbf{A}_{1} \mathbf{B}_{2}$; $A_{2} B_{2} ; A_{3} B_{2} ; A_{1} B_{3} ; A_{2} B_{3}$ dan $A_{3} B_{3}$ sebesar: 1,$61 ; 2,93 ; 1,68 ; 1,74 ; 4,01 ; 2,71 ; 3,64 ; 3,81$ dan 1,83 me/100 g.Terjadinya peningkatan nilai KTK tanah diduga disebabkan oleh adanya sumbangan bahan organik dari keong mas yang ditambahkan. Menurut Hardjowigeno (2003), bahan organik akan berpengaruh terhadap peningkatan KTK tanah sehingga menambah kemampuan tanah untuk mempertukarkan unsur hara.

Pada Tabel secara umum terlihat adanya pengaruh interaksi yang nyata antara pemberian jenis komposisi keong mas dan lama inkubasi yang berbeda terhadap nilai

KTK tanah. Perlakuan ini dapat meningkatkan dan menurunkan nilai KTK tanah. Pada pemberian daging keong mas KTK tanah mengalami peningkatan pada lama inkubasi 3 minggu dari inkubasi 2 minggu sebesar $1,08 \mathrm{me} / 100 \mathrm{~g}$ dan turunan setelah diinkubasi 4 minggu sebesar 0,21 me/100 g. Perlakuan penambahan cangkang + daging keong mas dapat meningkatkan KTK tanah dari lama inkubasi 2 minggu sebesar $1,04 \mathrm{me} / 100 \mathrm{~g}$ setelah diinkubasi 3 minggu, mengalami penurunan setelah diinkubasi 4 minggu sebesar $0,88 \mathrm{me} / 100 \mathrm{~g}$. Setelah dilakukan perbandingan nilai Ca-dd tanah setelah perlakuan dengan kriteria Ca-dd tanah terlihat bahwa ada pengaruh pemberian keong mas dengan

Tabel 9. Hasil Analisis Ca-dd tanah setelah perlakuan (me/100g).

\begin{tabular}{llllc}
\hline \multirow{2}{*}{$\begin{array}{llll}\text { Komposisi Keong Mas } \\
\text { (A) }\end{array}$} & \multicolumn{2}{c}{ Lama Inkubasi (B) } & \multicolumn{2}{c}{ Rata - rata } \\
\cline { 2 - 5 } Cangkang & $2,82(\mathrm{r}) *$ & $2,58(\mathrm{r}) *$ & $2,93(\mathrm{r}) *$ & 2,78 a \\
Daging & $1,63\left(\mathrm{r}^{*}\right)$ & $2,02(\mathrm{r})^{*}$ & $1,75(\mathrm{sr})^{*}$ & $1,80 \mathrm{c}$ \\
Cangkang + Daging & $1,98(\mathrm{sr}) *$ & $2,35(\mathrm{r}) *$ & $2,10(\mathrm{r})^{*}$ & 2,14 b \\
\hline Rata - rata & 2,14 & 2,32 & 2,26 & - \\
\hline KK & $14,27 \%$ & & & \\
\hline
\end{tabular}


Tabel 10. Hasil Analisis Mg-dd Tanah setelah perlakuan (me/100g).

\begin{tabular}{|c|c|c|c|}
\hline \multirow{2}{*}{$\begin{array}{c}\text { Komposisi Keong } \\
\text { Mas (A) }\end{array}$} & \multicolumn{3}{|c|}{ Lama Inkubasi (B) } \\
\hline & 2 minggu & 3 minggu & 4 minggu \\
\hline Cangkang & $0,27(\mathrm{sr}) * \mathrm{~A}$ b & $0,25(\mathrm{sr}) * \mathrm{~A} b$ & $0,25(\mathrm{sr}) * \mathrm{~A} \mathrm{c}$ \\
\hline Daging & $0,44\left(r^{*}\right)$ A a & $0,32(\mathbf{s r}) * \mathbf{B}$ a & $\mathbf{0 , 3 2}(\mathbf{s r}) * \mathbf{B}$ a \\
\hline Cangkang + Daging & $0,28(\mathrm{sr}) * \mathrm{~A}$ b & $0,27(\mathbf{s r})^{*} \mathbf{A} \mathbf{b}$ & $0,28(\mathrm{sr}) * \mathrm{~A}$ b \\
\hline KK & $4,96 \%$ & & \\
\hline
\end{tabular}

jenis komposisi dan lama inkubasi yang berbeda terhadap Ca-dd tanah. Hal ini ditandai dengan terjadinya peningkatan status Ca-dd tanah dari kriteria sangat rendah menjadi rendah, kecuali pada perlakuan $A_{2} B_{1}, A_{3} B_{1}$ dan $A_{2} B_{3}$ tidak terjadi peningkatan kriteria Ca-d tanah setelah perlakuan.

Terjadinya peningkatan kriteria Cadd tanah setelah perlakuan diduga akibat adanya sumbangan dari Ca yang ada pada keong mas. Dimana keong mas yang ditambahkan mengandung unsur $\mathrm{Ca}$ sebanyak 28,33 ppm pada cangkang dan 6,61 ppm pada dagingnya.

Pada Tabel 10 terlihat lama inkubasi memberikan pengaruh yang nyata pada perlakuan $A_{2}$ dan perbedaan komposisi keong mas memberikan pengaruh yang nyata terhadap ketersediaan Mg-dd tanah.
Nilai Mg-dd tertinggi dijumpai pada perlakuan $\mathbf{A}_{2} \mathbf{B}_{1}$. Terjadinya peningkatan Mg-dd tanah diduga berasal dari sumbangan Mg yang ada pada daging keong mas. Pada perlakuan $\mathrm{B}_{2}$ dan $\mathrm{B}_{3}$ terjadi penununan $\mathrm{Mg}$ dd, meskipun berbeda tidak nyata. Penurunan ini diduga akibat dari penggunaan Mg oleh mikroorganisme, sebagaimana Nyakpa et al (1988) menyatakan bahwa salah satu faktor kehilangan Mg dalam tanah adalah akibat dimanfaatkan oleh mikroorganisme hidup.

Berdasarkan kriteria K-dd tanah terlihat bahwa secara umum terjadi perubahan status K-dd tanah setelah perlakuan, dimana K-dd tanah sebelum perlakuan adalah $0,05 \mathrm{me} / 100 \mathrm{~g}$. Hal ini ditandai dengan berubahnya kriteria K-dd tanah dari sangat rendah menjadi rendah dan sedang.

Tabel 11. Hasil Analisis K-dd tanah (me/100) setelah perlakuan.

\begin{tabular}{lccc}
\hline \multicolumn{1}{c}{ Komposisi } & \multicolumn{3}{c}{ Lama Inkubasi (B) } \\
\cline { 2 - 4 } \multicolumn{1}{c}{ Keong Mas (A) } & 2 minggu & 3 minggu & 4 minggu \\
\hline Cangkang & $\mathbf{0 , 4 0}\left(\mathbf{r}^{*}\right)$ & $\mathbf{0 , 5 0}\left(\mathbf{s d}^{*}\right)$ & $\mathbf{0 , 4 2}\left(\mathbf{s d}^{*}\right)$ \\
Daging & $\mathbf{0 , 5 7}\left(\mathrm{sd}^{*}\right)$ & $\mathbf{0 , 4 3}\left(\mathrm{sd}^{*}\right)$ & $\mathbf{0 , 2 4}\left(\mathbf{r}^{*}\right)$ \\
Cangkang + Daging & $\mathbf{0 , 3 8}\left(\mathbf{r}^{*}\right)$ & $\mathbf{0 , 3 8}\left(\mathbf{r}^{*}\right)$ & $\mathbf{0 , 4 2}\left(\mathbf{s d}^{*}\right)$ \\
\hline KK & $\mathbf{2 9 , 9 2 \%}$ & & \\
\hline
\end{tabular}


Tabel 12. Hasil Analisis Na-dd tanah (me/100g) setelah perlakuan.

\begin{tabular}{|c|c|c|c|}
\hline \multirow{2}{*}{$\begin{array}{c}\text { Komposisi Keong } \\
\text { Mas (A) }\end{array}$} & \multicolumn{3}{|c|}{ Lama Inkubasi (B) } \\
\hline & 2 minggu & 3 minggu & 4 minggu \\
\hline Cangkang & $0,44\left(\mathrm{sd}^{*}\right) \mathrm{A}$ b & $\mathbf{0 , 4 0}\left(\mathrm{sd}^{*}\right) \mathrm{A}$ a & $\mathbf{0 , 5 1}\left(\mathbf{s d}^{*}\right) \mathrm{A} \mathbf{a}$ \\
\hline Daging & $0,74\left(\mathrm{sd}^{*}\right) \mathrm{A}$ a & $\mathbf{0 , 5 0}\left(\mathbf{s d}^{*}\right) \mathrm{C} \mathbf{a}$ & $0,58\left(\mathbf{s d}^{*}\right) \mathbf{B}$ a \\
\hline Cangkang + Daging & $0,41\left(\mathrm{sd}^{*}\right) \mathrm{A} b$ & $0,44\left(\mathrm{sd}^{*}\right) \mathrm{A} \mathbf{a}$ & $0,49\left(\mathbf{s d}^{*}\right) \mathrm{A}$ a \\
\hline KK & $8,9 \%$ & & \\
\hline
\end{tabular}

Hasil analisis Na-dd tanah setelah perlakuan yang dibandingkan dengan kriteria Na-dd tanah menunjukkan adanya pengaruh penambahan keong mas dengan komposisi dan lama inkubasi yang berbeda terhadap status Na-dd tanah. Hal ini ditandai dengan meningkatnya kriteria Nadd tanah dari sangat rendah menjadi sedang. Na-dd tanah sebelum periakuan adalah 0,36 me/100 g.

\section{KESIMPULAN}

Dari hasil penelitian dapat disimpulkan bahwa Penambahan keong mas dengan komposisi dan lama inkubasi yang berbeda dapat meningkatkan beberapa sifat kimia dan status hara tanah. Komposisi dan lama inkubasi terbaik adalah pada perlakuan $A_{2} B_{3}$ (Daging Keong mas dan lama inkubasi 4 minggu).Pada perlakuan ini terjadi penubahan $\mathrm{pH}$ tanah dari 5,01 menjadi 6,2 , Al-dd dari 3,12 menjadi tu, N-total dari 0,13(\%) menjadi $0,28(\%)$, KTK dari 11,37(me/100g) menjadi 13,2(me/100g), dan Ca-dd, Mg-dd, K-dd dan Na-dd secara berturut turut berobah dari $0,7,0,24,0,05$, 0,36 (me/100) menjadi 2,1, 0,28, 0,42 dan
0,49 (me/100g).

\section{DAFTAR PUSTAKA}

BPT-Sumbar. 2006. Tingkat Serangan hama di Sumbar. http://www.bpt.sumbar. $\quad$ go.id/ serangan-opt-files/ls\%20opt \% padi.htm(Agustus 2006).

Ismon. 2006. Keong Mas Silelet Perusak Padi http:/www.pikiran rakyat.com/cetak/2007/04

2007/19/cakrawala/03.htm(17 Juli 2007)

Pitojo, S. 1996. Petunjuk Pengendalian dan Pemanfaatan Keong Mas. Ungaran. Trubus Ariwidya. 106 hal.

Prasetyo, B.H. dan Suriadikarta, D.A. 2006.

Karakteristik, Potensi dan Teknologi Pengelolaan Ultisol Untuk Pengembangan Pertanian lahan Kering Indonesia. J.Litbang Pertanian (25):29-47

Susanto, H. 1995. Siput Murbei Pengendalian dan Pemanfaatannya. Yogyakarta.

Syukur, A. 2005. Pengaruh Pemberian Bahan Organik Terhadap Sifat-sifat Tanah dan Pertumbuhan Caisim di 
Tanah Pasir Pantai. J.Ilmu Tanah dan

Lingkungan Fak. Pertanian

Universitas Gajah Mada 5(1):30-38.
Sebastian, 2000. Management Options for The Golden apple snail http:/www. Applesnail.net (16 Mei 2007).

Winarso, S. 2005. Kesuburan Tanah. Yogyakarta. Gava media. 269 hal. 